\title{
Ю.К. Якимович
}

\section{ПРОБЛЕМЫ И ПЕРСПЕКТИВЫ ДИФФЕРЕНЦИАЦИИ УГОЛОВНОГО СУДОПРОИЗОДСТВА}

\begin{abstract}
Рассматриваются проблемы и перспективы дифференциации уголовного судопроизводства. Утверждается, что современный уголовный процесс России чрезмерно дифференцирован и необходимо в разумных пределах его унифицировать. Критикуется дознание в сокращённой форме. Предлагается вернуться к протокольному досудебному производству. Большинство уголовных дел в суде первой инстанции должно рассматриваться в обычном порядке и коллегиально.
\end{abstract}

Ключевые слова: основные, дополнительные и особые производства, формы предварительного расследования, упрощенное дознание, протокольное досудебное производство, коллегиальное рассмотрение дел в судаx.

Ни для кого не секрет, что действующий УПК РФ можно критиковать бесконечно, в том числе и в плане проблем дифференциации уголовного судопроизводства.

Во-первых, это уже далеко не тот УПК, которым он был в момент принятия. Причем постоянные изменения и дополнения носили и носят нередко ведомственный конкурентный характер, часто взаимно противоречивый. С научной общественностью законопроекты не обсуждаются, и нередко мы узнаем о них, когда они уже стали законами.

Наверное, это будет не совсем логичным, но я, последовательный сторонник дифференциации уголовного судопроизводства, недавно опубликовал статью под названием «От чрезмерной дифференциации к разумной унификации уголовного судопроизводства». Не предвидя негативные последствия, законодатель чрезмерно увлекся дифференциацией уголовного процесса. Появляются все новые производства как по уголовным делам, так и особые. Уголовный процесс тем самым размывается, утрачивается, как правильно не раз отмечал в своих работах М.К. Свиридов, его стержень [1, с. $33 ; 2$, с. 267$]$.

В целом, являясь сторонником судебного контроля, осуществляемого в рамках особых производств, должен признать, что он приобрел тотальный характер.

Достаточно сказать, что можно насчитать десятки судебно-контрольных производств (ст. 125, ч. 2 ст. 29 , гл. 18 , ч. 5 ст. 165 и др.).

Чрезмерное расширение судебного контроля приводит к тому, что:

1) следователь все более утрачивает процессуальную самостоятельность;

2) суды общей юрисдикции перегружены этими делами, а значит, у судей меньше остается времени для качественного рассмотрения уголовных дел по существу.

Негативным моментом является также и то, что законодатель устанавливает различные порядки практически по каждому из особых судебноконтрольных производств. Порядок рассмотрения жалоб на действия и решения, принимаемые орга- нами предварительного производства, установлен ст. 125 УПК РФ, и он отличается от порядка получения судебного решения для производства в установленных случаях следственных действий (ст. 165 УПК РФ).

Порядок получения судебного решения для избрания в качестве меры пресечения заключение под стражу установлен ст.ст. 108-109 УПК РФ, отстранения от должности - ст. 114 УПК и так далее.

Представляется, что в разумных пределах можно было бы унифицировать процессуальную форму для судебно-контрольных производств.

Много вопросов вызывает и дифференциация основного (по уголовным делам) производства. Что касается досудебного производства, то на первый взгляд оно достаточно дифференцированно: предусмотрено три формы предварительного расследования:

1) сокращенное дознание;

2) обычное дознание;

3) предварительное следствие.

Вместе с тем нельзя не отметить, что полицейское дознание в обычной форме мало чем отличается от предварительного следствия. А ведь когда УПК РФ только начинал действовать, дознание весьма существенно отличалось от предварительного следствия.

Дознание производилось только по очевидным преступлениям (по делам, возбужденным в отношении конкретных лиц) и в краткие сроки - 10 суток. Причем срок этот мог быть продлен прокурором только на 15 суток, и не более того.

Лицо в качестве подозреваемого могло находиться по общему правилу также не более 10 суток и, во всяком случае, не более 25 суток, что в общемто не вызывало больших пререканий в процессуальной литературе.

Затем либо составлялся обвинительный акт, который ставил подозреваемого в положение обвиняемого, либо, если дознание необходимо было заменить следствием, следователь на общих основаниях должен был вынести постановление о привлечении лица в качестве обвиняемого и предъявить ему обвинение. 
При таких условиях дознание действительно можно считать упрощенной формой досудебного производства (предварительного расследования).

Однако последующие изменения, вносимые в УПК, постепенно сближали две формы предварительного расследования. И к настоящему времени дознание как самостоятельная форма предварительного расследования практически мало чем отличается от предварительного следствия, во всяком случае по процессуальной форме.

Особую озабоченность вызывает тот факт, что теперь лицо без предъявления обвинения, в положении подозреваемого может находиться в течение 6 месяцев и даже одного года: в тех случаях, когда уголовное дело возбуждается в отношении конкретного лица, а затем сроки дознания продлеваются прокурором.

В любом случае возникает закономерный вопрос о необходимости одновременного существования в одном ведомстве (МВД) и подразделений дознания, и следственных органов.

И дознаватели, и следователи занимаются одним и тем же - расследованием преступлений. Разница лишь в подследственности, в категории расследуемых дел. При этом по качественным показателям: образовательному уровню (наличию специального юридического образования), стажу работы и т.д. дознаватели и следователи в системе МВД находятся на одном уровне, и опытный дознаватель вполне мог бы заменить следователя.

Это вовсе не означает, что досудебное производство не должно быть дифференцированным, а дознание как самостоятельная форма предварительного расследования упразднено. Но для действительной дифференциации, прежде всего, необходимы организационно-правовые предпосылки - образование наконец-то следственного комитета как единого и единственного вневедомственного органа, осуществляющего предварительное расследование. Создание Следственного комитета РФ не решило проблемы. Возникли лишь дополнительные трудности во взаимодействии между следователями разных ведомств, поскольку одновременно был разрушен единый координационный центр в лице органов прокуратуры, осуществлявшей процессуальное руководство предварительным следствием независимо от ведомственной подчиненности следователей.

Как мне представляется, разобщенность следователей разных ведомств будет лишь усугубляться. Каждое из ведомств начнет издавать свои ведомственные нормативные акты, инструкции, существенно различающиеся между собой и размывающие единое уголовно-процессуальное законодательство.

Образование единого Следственного комитета подразумевает, что в его структуре могут создаваться специализированные следственные подразделения: по расследованию убийств; преступлений, совершенных организованными преступными формированиями; коррупционных преступлений и т.д. Но при этом будет сохраняться единая политика, еди- ное процессуальное руководство, единая нормативная база.

Вместе с тем создание Следственного комитета не означает вовсе, что его следователи будут расследовать все без исключения преступления.

Подразделения дознания в МВД должны быть сохранены для выполнения трех задач:

1. Расследования очевидных нетяжких преступлений в краткие, не более 10 суток, сроки.

2. Оказание помощи следователям в форме выполнения их отдельных поручений.

3. Возбуждение уголовных дел и производство по ним необходимых следственных действий, когда по этим делам предварительное следствие является обязательным.

Следует также отметить, что у дознавателя на данный момент чрезмерно много процессуальных руководителей: начальник подразделения дознания, начальник органа дознания, ещё и прокурор. Следует, на мой взгляд, за прокуратурой оставить только функцию надзора за соблюдением законов при производстве дознания.

Считаю также непродуманным решением исключение из уголовно-процессуального законодательства протокольного досудебного производства. Протокольная форма досудебной подготовки материалов доказала свою эффективность, хотя и были замечания к конкретным нормам. Но были и конкретные предложения по совершенствованию процессуального регулирования протокольного производства. Вместо того чтобы проанализировать и учесть эти предложения, законодатель вовсе исключил из уголовно-процессуального законодательства протокольное досудебное производство. Между тем в некоторых государствах, бывших республиках СССР (например, Азербайджан), протокольная форма досудебного производства сохранена.

Представляется, что в УПК РФ, наряду с дознанием и предварительным следствием, следует возродить протокольное досудебное производство.

Мне могут возразить, что взамен протокольного производства законодатель предусмотрел дознание в сокращенной форме (глава 32.1 УПК). Однако институт дознания в сокращенной форме подвергся вполне обоснованной критике, как учеными, так и практиками. Начальники подразделений дознаний, с которыми мне довелось побеседовать, не видят смысла в использовании этой формы дознания. Они считают, что в сроки, указанные в главе 32.1 УПК, по очевидным преступлениям можно успешно начать и окончить дознание в обычной форме. И тогда не будет проблем с возвращением дела с упрощенной формой дознания для производства дознания в обычном порядке прокурором или судом по желанию защитника или потерпевшего.

Представляется, что Ф3 от 4 марта 2013 года внес такие изменения в УПК РФ, негативные последствия которых скажутся уже в ближайшие годы. Этот Закон не был как следует теоретически проработан. Претерпевает существенные изменения ста- 
дия возбуждения уголовного дела, по существу сливаясь с дознанием. Расширяется перечень источников доказательств (обвинения), до невозможного упрощается судебная процедура рассмотрения этих дел. По большому счету, суд в этих производствах не нужен. В целом же предусмотренное главой 32.1 УПК дознание в сохранившейся (также - в упрощенной) форме сильно напоминает производство по административным делам и, на мой взгляд, вовсе не подходит для уголовного процесса.

Вполне закономерно, что многие ученые весьма негативно отнеслись к мартовским 2013 года изменениям УПК РФ [3, с. 20].

Стоит также отметить, что многие десятилетия ведутся споры о том, имеется ли необходимость в сохранении стадии возбуждения уголовного дела в качестве самостоятельной стадии уголовного процесса $[4$, с. 110]. Следует заметить, что ни в одной стране (кроме некоторых государств, входивших ранее в состав СССР) такой стадии нет. Вместо института «Возбуждение уголовного дела» там предусматривается другой институт - «Возбуждение уголовного преследования».

Последние изменения законодательства Российской Федерации, начиная с момента принятия УПК РФ, приводят меня к выводу о том, что, в конечном счете, стадию возбуждения уголовного дела заменит возбуждение уголовного преследования. Оно будет выступать либо в качестве самостоятельной стадии, либо будет сведено к вынесению процессуального акта.

Что касается производства по уголовным делам в суде первой инстанции, то оно в достаточной степени дифференцировано. Кроме обычного производства имеются как упрощенные (производство по делам частного обвинения у мирового судьи, производства, предусмотренные главами 40, 40 1 УПК РФ), так и производства с более сложными процессуальными формами (производство по делам несовершеннолетних, в суде с участием присяжных, в отношении отдельных категорий лиц).

Однако не все решения законодателя (особенно это касается упрощенных судебных производств) получили одобрение в научном сообществе.

Так, при рассмотрении уголовных дел в порядке, предусмотренном главами 40 и $40^{1}$ УПК, вовсе не производится судебное следствие. Фактически дело не рассматривается, а лишь разрешается судом (по аналогии с судебным приказом). Не действует в этих производствах основополагающий принцип судебного разбирательства - непосредственность. По сути, обвинительный приговор строится на признании обвиняемым своей вины. В принципе, нельзя вовсе исключить из уголовного судопроизводства институт судебного приказа. Но не в таком масштабе, как это происходит сейчас, когда до $80 \%$ дел рассматриваются в упрощенном порядке.

Дифференциация судебного производства не должна сводиться лишь к упрощению или усложнению процессуальных форм судебной деятельности.
Она должна касаться и состава суда, рассматривающего различные категории дел. Представляется абсолютно недопустимым существующее ныне положение, когда абсолютное большинство уголовных дел рассматривается в судах первой инстанции единолично. Коллегиально рассматривались уголовные дела по первой инстанции и в Российской империи, и в Советской России. Причем по УПК РСФСР 1960 года коллегиально рассматривались все без исключения уголовные дела. Итак:

1. Дифференциация уголовного судопроизводства предполагает разграничение уголовного процесса не только по степени сложности процессуальной формы, но и по другому критерию - направленности производства, выраженной в его предмете и задачах. По этому критерию все уголовно-процессуальные производства можно подразделить на:

1.1. Основные - производства по уголовным делам.

1.2. Дополнительные - производства, возникающие в процессе реального исполнения приговора (не путать со стадией исполнения приговора).

1.3. Особые - производства, материальной основой которых являются нормы административного (глава 51 УПК РФ), гражданского (гражданский иск в уголовном процессе), конституционного (ч. 2 ст. 29, ст. 125 УПК РФ) и иных материальных отраслей права (возмещение вреда в порядке реабилитации).

2. Разграничив все производства по их направленности, далее следует применить критерий сложности процессуальной формы.

3. Применив этот критерий к производствам основным (по уголовным делам), мы получим:

3.1. Обычное производство, досудебная деятельность в котором осуществляется в форме предварительного следствия, а в суде первой инстанции дело рассматривается и разрешается в обычном порядке.

3.2. Упрощенное производство.

3.3. Производства с более сложными процессуальными формами.

4. Досудебное производство должно предполагать наличие в нем:

4.1. Протокольного досудебного производства.

4.2. Полицейского дознания (ускоренного и упрощенного в сравнении с предварительным следствием).

4.3. Предварительного следствия, производимого следователями единого следственного органа.

5. Дифференциация должна предполагать в том числе и дифференциацию судебных составов, рассматривающих уголовные дела по первой инстанции.

В целом же последние изменения УПК РФ привели к тому, как уже отмечалось ранее, что около $80 \%$ уголовных дел судами первой инстанции фактически не рассматриваются, а лишь разрешаются. По этим делам не проводится судебного следствия, а значит, не действуют основополагающие судебные принципы, в том числе принцип непосредственности. 
И если говорить откровенно, то мы вновь возвращаемся к тем временам, когда «царицей доказательств» являлось признание обвиняемым своей вины, что не может быть допустимым в уголовном судопроизводстве XXI века.
Дифференциация уголовного судопроизводства должна проводиться в разумных пределах и не приводить к упрощенчеству в уголовном процессе, о чем я уже говорил и писал много раз.

\section{ЛИТЕРАТУРА}

1. Свиридов М.К. О методе уголовно-процессуального регулирования и сфере его действия // Право на судебную защиту в уголовном процессе: Европейские стандарты и российская практика: Сб. статей по материалам Междунар. науч.практич. конф. Томск, 20-22 сентября 2007 г. / под ред. М.К. Свиридова. Томск: Изд-во Том. ун-та, 2007. С. 33-37.

2. Свиридов M.К. Некоторые вопросы установления истины в уголовном процессе // Уголовно-процессуальные и криминалистические чтения на Алтае / под ред. В.К. Гавло. Барнаул: Изд-во АлтГУ, 2008. Вып. 7-8. С. $267-271$.

3. Воронин O.B. Перспективы совершенствования существующих форм контроля за предварительным следствием // Законы России: опыт, анализ, практика: ежемесячный правовой журнал. 2008. № 11. С. 19-22.

4. Андреева О.И. О необходимости стадии возбуждения уголовного дела в современном уголовном процессе России // Вестник Томского государственного университета. Сер. Право. 2012. № 356. С. 109-112.

\section{PROBLEMS AND PROSPECTS OF THE DIFFERENTIATION OF CRIMINAL PROCEEDINGS}

Russian Journal of Criminal Law, 2015, no. 2(6), pp. 63-66. DOI 10.17223/23088451/6/12

Yakimovich Yury K., Tomsk State University (Tomsk, Russian Federation). E-mail: crim.just@mail.ru

Keywords: basic, additional and special proceedings, forms of preliminary investigation, simplified inquiry, pre-trial protocol, collective judicial proceedings.

The article deals with the problems and prospects of differentiation of criminal proceedings. The author believes that the modern Russian criminal process is excessively differentiated mainly due to the increased number of forensic control procedures. The author expresses his concern about the excessive desire to simplify the criminal proceedings, which often leads to the oversimplification. On the basis of the study, the authors concludes about the following: differentiation of the criminal proceedings means that the criminal process is differentiated not only by the degree of complexity of the procedural form, but also by another criterion - the focus of the proceedings that is expressed in its subject and objectives. By this criterion all criminal procedures can be divided into: basic (proceedings in criminal cases), additional (proceedings that occur during the specific performance of the sentence (not to be confused with the stage of the sentence execution), and special (proceedings based on the norms of administrative (Section 51 of the Code of Criminal Procedure), civil (civil suits in criminal trials), constitutional (Part 2, Article 29, Article 125 of the Code of Criminal Procedure) and other branches of law (indemnification as rehabilitation).

With the criterion of complexity of the procedural form applied, we can divide all basic proceedings (in criminal cases) into: - regular proceedings, the pre-trial activity in which takes the form of the preliminary investigation, and the case is considered and resolved in the trial court case in the ordinary way; - simplified proceedings; - proceedings with more complex procedural forms. Pre-trial proceedings should include: - the protocol of the pre-trial proceedings; - police inquiry (accelerated and simplified in comparison to the preliminary investigation); - the preliminary investigation by investigators of a single investigative body.

The differentiation presupposes the differentiation of judges handling criminal cases at the first instance.

In general, the recent changes in the Russian Federation Code of Criminal Procedure resulted, as it has been stated above, in the situation when $80 \%$ of criminal cases are not handled by the courts of first instance, but only resolved. There is no judicial investigation for these cases, which means that the fundamental legal principles, including the principle of immediacy, do not operate.

Differentiation of the criminal proceedings should be carried out within reasonable limits and should not lead to its oversimplification.

\section{REFERENCES}

1. Sviridov, M.K. (2007) O metode ugolovno-protsessual'nogo regulirovaniya i sfere ego deystviya [On the method of regulation of the criminal procedure and its scope]. In: Sviridov, M.K. (ed.) Pravo na sudebnuyu zashchitu v ugolovnom protsesse: Evropeyskie standarty i rossiyskaya praktika [The right to judicial protection in criminal proceedings: European and Russian practices]. Tomsk: Tomsk State University. pp. 33-37.

2. Sviridov, M.K. (2008) Nekotorye voprosy ustanovleniya istiny v ugolovnom protsesse [Some questions of establishing the truth in a criminal trial]. In: Gavlo, V.K. (ed.) (2008) Ugolovno-protsessual'nye i kriminalisticheskik chteniya na Altae [Criminal procedure and criminalistic Readings in the Altai]. Barnaul: Altai State University. pp. 267-271.

3. Voronin, O.V. (2008) Perspektivy sovershenstvovaniya sushchestvuyushchikh form kontrolya za predvaritel'nym sledstviem [Prospects for improving the existing forms of control over preliminary investigation]. Zakony Rossii: opyt, analiz, praktika. 11. pp. 19-22.

4. Andreeva, O.I. (2012) On the necessity of criminal case instituting in present-day criminal proceedings in Russia. Vestnik Tomskogo gosudarstvennogo universiteta - Tomsk State University Journal. 356. pp. 109-112. (In Russian). 